\title{
In Situ Technologies for Studying Deep-Sea Hotspot Ecosystems
}

By Antje Boetius and Frank Wenzhöfer

Cold seeps, hydrothermal vents, deep water coral reefs, and submarine canyon systems are hotspot habitats characterized by intermediate to high fluid advection. They are shaped by a complex interplay of physical, biological, geochemical, and geological processes. Biogeochemical and physicochemical gradients in these ecosystems are frequently extremely steep and temporally and spatially variable. Zones of elevated microbial activity, such as the methane-sulfate interface at cold-seep sites, usually encompass no more than a few millimeters. Recovery of samples for further shipboard analysis from such hotspot zones generally causes severe artifacts in the biogeochemical gradients. Hence, to quantify chemical gradients, microbial processes, and transport rates in deep-sea hotspot ecosystems, we have developed and operated a variety of specialized in situ instruments (Figure 1).

To find our way and carry out multiple measurements in specific locations, different habitats are marked with physical markers and/or beacons to acoustically guide the deep submergence vehicles handling our tools (Figure 1a). Sediments and water samples are retrieved using push cores and revolving water bottles, respectively. To determine high-resolution chemical gradients, we use the microprofiler, which allows us to characterize the geochemical zonation of sedimentary habitats at high vertical resolution $(>50 \mu \mathrm{m})$ for a number of different components $\left(\mathrm{pH}, \mathrm{T}, \mathrm{H}_{2} \mathrm{~S}\right.$, $\mathrm{CO}_{2}, \mathrm{O}_{2}, \mathrm{Ca}^{2+}$; see Figure $1 \mathrm{~b}$ ). We can also characterize the bottom water around accumulations of organisms using so-called "handheld" sensors for a similar range of chemical substances (Figure 1c). For two-dimensional imaging of oxygen distribution at a similar scale, we use the planar optode (Figure 1d). To quantify the anaerobic consumption of sulfate (e.g., for the oxidation of methane), intact seafloor sediments are injected with tracer substances using the INSINC module (Figure 1e). Benthic chambers are used to measure exchange rates and total benthic fluxes in order to calculate respiration rates and the emission of methane and sulfide (Figure 1f), and the DeepFlow instrument measures the advective flow of geofluids.

These tools are all deployed by remotely operated underwater vehicles (ROVs and crawlers) and submersibles, which enable targeted sampling and precise positioning of instruments at selected spots under visual control. Adaptations include miniaturization of the measuring devices and improved operability, such as multiple uses during a single dive and longterm measurements. These deployments are carried out in collaboration with the leading international research institutions that operate ROVs, such as the 6000-m Victor (Institut français de recherche pour l'exploitation de la mer [Ifremer]), the 4000-m Quest (Center for Marine Environmental Studies, University of Bremen [MARUM]), and the 4800-m Isis (National Oceanography Centre, Southampton [NOCS]), but they can also be used on submersibles and benthic crawlers. These in situ technology achievements are a key step forward in the development of deep-sea observatories for long-term ecosystem studies (e.g., the EU-NoE European Seafloor Observatory Network [ESONET] project). שe

Antje Boetius (aboetius@mpi-bremen.de) is Head, Microbial Habitat Group, Max Planck Institute for Marine Microbiology, and Professor, Jacobs University Bremen, Bremen, Germany. Frank Wenzhöfer is Scientist, Habitat Group, Max Planck Institute for Marine Microbiology, Bremen, Germany.

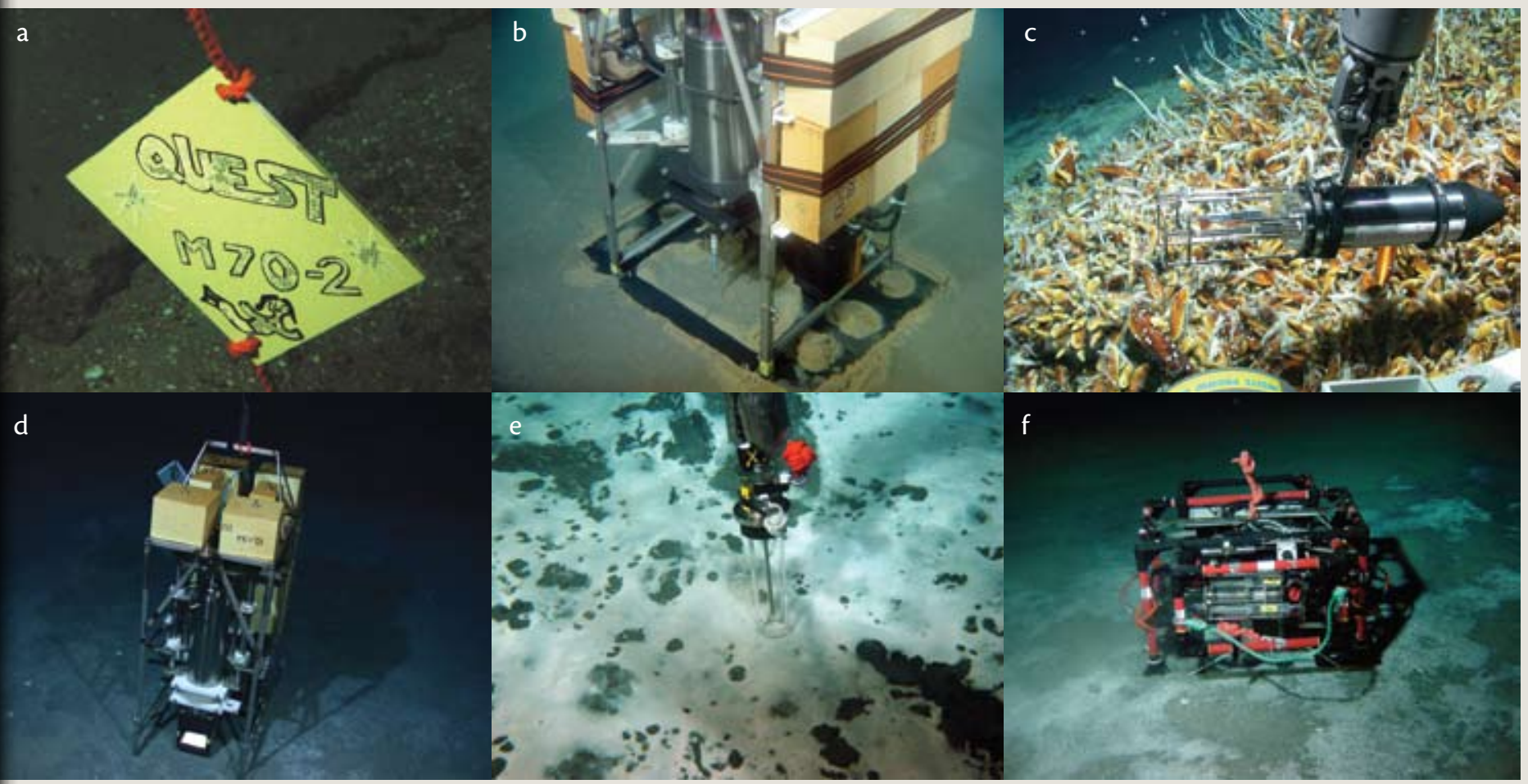

